\title{
Importance of In-Hospital Prospective Registry and Infectious Endocarditis Heart Team to Monitor and Improve Quality of Care in Patients with Infectious Endocarditis
}

\author{
Guy Van Camp ${ }^{1, *(D)}$, Monika Beles ${ }^{1}$, Martin Penicka ${ }^{1}$, Dan Schelfaut ${ }^{1}$, Stijn Wouters ${ }^{1}$, Herbert De Raedt ${ }^{1}$, \\ Eric Wyffels ${ }^{1}$, Jerrold Spapen ${ }^{1}$, Riwa Nasser ${ }^{1}$, Zsuzsanna Balogh ${ }^{2}$, Marzia Albano ${ }^{3}$, Hans De Beenhouwer ${ }^{4}$, \\ Kristien Van Vaerenbergh ${ }^{4}$, Frank Van Praet ${ }^{5}$, Ivan Degrieck ${ }^{5}$, Bernard Stockman ${ }^{5}$, Filip Casselman ${ }^{5}$ and \\ Carlos Collet ${ }^{1}$
}

Citation: Van Camp, G.; Beles, M.; Penicka, M.; Schelfaut, D.; Wouters, S.; De Raedt, H.; Wyffels, E.; Spapen,

J.; Nasser, R.; Balogh, Z.; et al. Importance of In-Hospital

Prospective Registry and Infectious Endocarditis Heart Team to Monitor and Improve Quality of Care in Patients with Infectious Endocarditis. J. Clin. Med. 2021, 10, 3832. https:// doi.org/10.3390/jcm10173832

Academic Editor: Giovanni La Canna

Received: 4 July 2021

Accepted: 23 August 2021

Published: 26 August 2021

Publisher's Note: MDPI stays neutral with regard to jurisdictional claims in published maps and institutional affiliations.

Copyright: (c) 2021 by the authors. Licensee MDPI, Basel, Switzerland. This article is an open access article distributed under the terms and conditions of the Creative Commons Attribution (CC BY) license (https:/ / creativecommons.org/licenses/by/ $4.0 /)$.
1 Cardiovascular Center, OLV Aalst, Moorselbaan 164, 9300 Aalst, Belgium; monika.beles@olvz-aalst.be (M.B.); martin.penicka@olvz-aalst.be (M.P.); dan.schelfaut@olvz-aalst.be (D.S.); Stijn.Wouters@olvz-aalst.be (S.W.); Herbert.De.Raedt@olvz-aalst.be (H.D.R.); Eric.Wyffels@olvz-aalst.be (E.W.); Jerrold.Spapen@olvz-aalst.be (J.S.); nasser.riwa@gmail.com (R.N.); Carlos.collet.bortone@olvz-aalst.be (C.C.)

2 Gottsegen Gyorgy National Institute of Cardilogy, Haller u. 29, 1096 Budapest, Hungary; zsuzsi.liliom@gmail.com

3 Cardiology Unit, S. Maria Nuova Hospital, Via Amendola 2, 42122 Reggio Emilia, Italy; marz.albano@gmail.com

4 Department of Microbiology, OLV Aalst, Moorselbaan 164, 9300 Aalst, Belgium; hans.de.beenhouwer@olvz-aalst.be (H.D.B.); kristien.van.vaerenbergh@olvz-aalst.be (K.V.V.)

5 Cardiovascular and Thoracic Surgery, OLV Aalst, Moorselbaan 164, 9300 Aalst, Belgium; frank.van.praet@olvz-aalst.be (F.V.P.); Ivan.Degrieck@olvz-aalst.be (I.D.);

Bernard.Stockman@olvz-aalst.be (B.S.); filip.casselman@olvz-aalst.be (F.C.)

* Correspondence: guy.van.camp@olvz-aalst.be

\begin{abstract}
Aim: To investigate the value of prospective in-hospital registry data and the impact of an infectious endocarditis heart team approach (IEHT) on improvement in quality of care and monitor outcomes in hospitalized patients with IE. Methods: Between December 2014 and the end of 2019, 160 patients were hospitalized in one centre with the definite diagnosis of infectious endocarditis (IE) and entered in a prospective registry. From 2017, an IEHT was introduced. Propensity score matching was used to assess the impact of an IEHT approach on clinical outcomes. Results: Median age was 72.5 y (62.75-80.00), diabetes was present in 33.1\%, chronic kidney disease in $27.5 \%$, COPD in $17.5 \%$, and a history of ischaemic heart disease in $30.6 \%$. Prosthetic valve IE was observed in $43.8 \%$ and device-related IE in $16.9 \%$ of patients. Staphylococcus $(37.5 \%)$ was the most frequent pathogen followed by streptococcus $(24.4 \%)$ and enterococcus $(23.1 \%)$. Overall, 30-day and 1-year mortality were $19.4 \%$ and $37.5 \%$, respectively. The introduction of prospective data collection and IE heart team was associated with a trend towards reduction of adjusted 1-year mortality (26.5\% IEHT vs. $41.2 \%$ controls, $p=0.0699$ ). An IEHT clinical decision-making approach was independently associated with a shorter length of stay $(p=0.04)$. Conclusions: Use of a prospective registry of IE coupled with a heart team approach was associated with more efficient patient management and a trend towards lower mortality. Prospective data collection and dedicated IEHT have the potential to improve patient care and clinical outcomes.
\end{abstract}

Keywords: infectious endocarditis; outcome; quality of care

\section{Introduction}

Infective endocarditis (IE) is a severe disease and is still associated with high morbidity and mortality [1-5]. Mortality rates vary considerably between different studies. In one of the latest largest registries, the Euro-Endo Registry, including possible and definite IE, in-hospital mortality was $17.1 \%$ [1]. Landmark guidelines in the field of IE report intrahospital mortality rates between 15-30\% [2,3]. In-hospital mortality is highly influenced 
by the local integrated care pathway. Moreover, strategies aiming at improving care in patients with acute IE have the potential to impact mortality rates. Recent literature reports 30 -day mortality of approximately $20 \%$, whereas 1 -year mortality reaches $40 \%[4,5]$.

Although the incidence of IE is low, between 3-10/100,000 per year, it increases with time despite improvements in diagnosis and treatment [6]. The complexity and heterogeneity of this disease coupled with the unabated mortality rate commits for a multidisciplinary integrated care pathway involving several specialities to pursue the best care for this fragile population. Current data on IE characteristics and impact of interventions on outcome remain scarce.

The aim of this study is (1) to demonstrate the value of in-hospital prospective data collection and an infectious endocarditis heart team approach (IEHT) decision-making pathway on the improvement in quality of care and outcomes in hospitalized patients with IE; and (2) to characterize the population of IE.

\section{Material and Methods}

\subsection{Study Design}

From December 2014, all patients hospitalized in the referral hospital OLV Aalst, Belgium, with the definite diagnosis of IE were included in a prospective registry (prespecified case report form). This registry from the Cardiovascular Centre OLV Aalst (CVCA) was created in accordance with the ethics committees of our institution. The need for written consent to participate in this research study was waived in view of its observational and anonymous nature. For this manuscript, patients entering the hospital between December 2014 and December 2019 were analysed. To be included, patients had to have the diagnosis of definite IE using the current ESC guidelines [2]. For each patient, a total of 225 variables was entered in this prospective database.

From January 2017, a multidisciplinary IEHT was organized. The IEHT was composed of cardiologists from the coronary care unit, cardiologists from the imaging and critical department, cardiac surgeons, microbiologists, neurologists, radiologists and specialists from nuclear medicine. They were all integrated in the management of the patients presenting with a suspicion of IE. From the introduction of the IEHT, all patients with a suspicion of IE were immediately admitted into the coronary care unit for close monitoring, and the IEHT was gathered the same day to decide the diagnostic and therapeutic pathways to follow for the next days, following the current ESC guidelines [2]. In the next days and weeks, patients' clinical condition were discussed weekly in the heart team meetings. Patients were stratified into those treated following the recommendations of the IEHT and controls (i.e., patient management decided outside the structure of the IEHT before introduction of the IE heart team).

The objectives of the present study are: (1) to assess the impact of an intervention in the clinical care pathway (i.e., IEHT coupled with prospective data collection) on clinical outcomes; (2) to define patient's characteristics and outcomes and place these results in perspective with the most recently published prospective registry data of the ESC-EORP EURO-ENDO registry and from other recent prospective registries [1,5,7-9].

For the evaluation of surgical indication in each case of IE, the recent ESC guidelines were used [2]. Cardiac device-related IE (CDRIE) was defined following the same ESC guidelines: an infection extending to the electrode leads, cardiac valve leaflets or endocardial surface [2]. All-cause death was assessed in-hospital, at 30 days, 6 months and 12 months. Length of stay was defined as the days from admission to discharge.

\subsection{Data Collection and Statistical Methodology}

Data were collected by a dedicated research nurse (MB) in cooperation with cardiologists, cardiac surgeons and microbiologists. Results of categorical variables were represented as counts and as proportions. Continuous variables were reported as medians with interquartile range (IQR) or means and standard deviations. For comparison of observed proportions in the different groups, chi-squared test with continuity corrections were used. For among-group comparison of continuous results, unpaired $t$ tests or 
Kruskal-Wallis non-parametric tests were used. In case of one sample testing of a variable on interval level, Wilcoxon rank sum test was performed. For time-to-event analysis, Kaplan-Meier survival curves were drawn. Differences in survival curves were analysed with logrank test. To compare differences in clinical outcomes between the period before and after the introduction of the registry and heart team approach, a propensity score matching was performed using a nearest neighbour. Patients were matched using 1:1 without replacement. Variables included in the propensity score were age, gender, diabetes, COPD, renal function (GFR) and presence of prosthetic valve (Figure A1). Cox regression models were used to assess independent predictors of mortality. Least square regression was used for the prediction of in-hospital length of stay. All results were considered statistically significant at $p<0.05$ level. Data were analysed using R statistical software version 3.6.2 of the R Foundation for Statistical Computing, Vienna, Austria.

\section{Results}

A total of 160 patients with the definite diagnosis of IE were included in this study. In the same period, 27 patients had the diagnosis of possible IE and were not included in the present analysis.

\subsection{Patient Characteristics and Comparison with Previous Registries}

Patients' characteristics are shown in Table 1. Median age was 72.5 y (62.75-80.00), diabetes was present in $33.1 \%$, chronic kidney disease in $27.5 \%$, COPD in $17.5 \%$, and a history of ischaemic heart disease in $30.6 \%$.

Table 1. Patient characteristics.

\begin{tabular}{|c|c|}
\hline Registry & CVCA \\
\hline$n$ hospitals & 1 \\
\hline$n$ countries & 1 \\
\hline Data collection period & 2014-2019 \\
\hline Cases included & Definite IE \\
\hline \multicolumn{2}{|l|}{ Demography: } \\
\hline $\mathrm{N}$ & 160 \\
\hline Median age in years (IQR) & $72.50(62.75 \pm 80.00)$ \\
\hline Age $\geq 65$ years & $112 / 160(70 \%)$ \\
\hline Age $\geq 80$ years & $44 / 160(27.5 \%)$ \\
\hline Females & $40 / 160(25 \%)$ \\
\hline \multicolumn{2}{|l|}{ History of cardiovascular diseases: } \\
\hline Heart failure & $33 / 160(20.6 \%)$ \\
\hline Congenital disease & $13 / 160(8.1 \%)$ \\
\hline Ischaemic heart disease & $49 / 160(30.6 \%)$ \\
\hline Peripheral arterial disease & $28 / 160(17.5 \%)$ \\
\hline Previous endocarditis & $15 / 160(9.4 \%)$ \\
\hline Intra-cardiac device & $44 / 160(27.6 \%)$ \\
\hline Presence of prosthetic valve & $75 / 160(46.9 \%)$ \\
\hline \multicolumn{2}{|l|}{ Risk factors and comorbidities: } \\
\hline Diabetes & $53 / 160(33.1 \%)$ \\
\hline Previous stroke/TIA & $14 / 160(8.8 \%)$ \\
\hline COPD/asthma & $28 / 160(17.5 \%)$ \\
\hline Chronic renal failure & $44 / 160(27.5 \%)$ \\
\hline Dialysis & $19 / 160(11.9 \%)$ \\
\hline HIV & $2 / 160(1.2 \%)$ \\
\hline Chronic liver disease & $13 / 160(8.2 \%)$ \\
\hline Cancer & $27 / 160(16.9 \%)$ \\
\hline Intravenous drug dependency & $3 / 160(1.9 \%)$ \\
\hline Intravenous catheter & $12 / 160(7.5 \%)$ \\
\hline Invasive procedure within 60 days & $43 / 160(26.9 \%)$ \\
\hline
\end{tabular}

Overview of basic study specifications, demography, cardiovascular disease history, risk factors and comorbidities in the CVCA. 
Patient characteristics, clinical presentation, aetiology and comparison with contemporary IE registries are shown in Tables A1-A3. Staphylococcus (37.5\%) was the most frequently encountered organism responsible for IE. Enterococcus, however, was almost as frequently present than streptococcus species $(24.4 \%)$ in CVCA, representing $23.1 \%$ of all IE cases. This is higher compared to all other registries. From these 37 patients, 26 had a colonoscopy with resection of a polyp in 19 patients, unmasking 1 carcinoma, 2 high-grade, 3 moderate and 11 low-grade dysplasia.

Presence of a prosthetic valve IE $(46.9 \%)$ and a cardiac electronic device $(27.6 \%)$ were frequently present and more frequently compared to previous reports (Table A3). Similarly, prosthetic valve IE $(43.8 \%)$ and CDRIE $(16.9 \%)$ were more frequently encountered compared to EURO-ENDO (30.1\% and 9.9\%) and other registries. (Table A3) Whatever risk estimation tool is used, the risk profile of the CVCA IE registry was high. A Charlson comorbidity index not adjusted for age $\leq 80$ was present in $32 \%$ of IE, Euroscore II $\geq 10$ was present in $62.5 \%$ of IE, STS score $\geq 4$ in $60.6 \%$, KATZ ADL $<4$ in $50.6 \%$, frailty score $>4$ in $59 \%$ and global risk assessment was high or prohibitive in $42 \%$ and $29.3 \%$ of IE patients [3,10-13] (Figure A2, Table A4). Entrance site and acquisition of IE (Table A5) and diagnostic details from the different imaging modalities (Table A6) are shown in the Appendix A. Transthoracic echocardiography (TTE) was less often performed (53\%) and transoesophageal echocardiography (TOE) more often performed compared to other registries. PET-CT was more often performed (28.8\%), but MDCT was less often performed (3.1\%). The sensitivity of TTE, TOE and PET-CT were comparable between CVCA and other registries with a sensitivity of TTE in CVCA of $50 \%$, of TOE $88 \%$ and of PET-CT of $66 \%$. Valvular lesions and complications during the course of the intra-hospital observation are also detailed in the Appendix A (Tables A7 and A8).

\subsection{Treatment and Clinical Outcomes}

Surgery was performed in 82/160 (51.3\%) patients in the CVCA registry comparable to the EURO-ENDO registry that reported $51.2 \%$ of IE patients undergoing surgery. The proportion of patients who needed surgery but in whom surgery was not performed were also comparable with $17.5 \%$ in CVCA and $18.1 \%$ in Euro-endo $(p>0.05)$. In EURO-ENDO, more patients received a mechanical prosthesis compared to CVCA $(35.1 \%$ versus $3.1 \%$; $p<0.001)$. Despite this older age, repair was performed equally in CVCA versus EUROENDO (11.1\% versus $19.5 \%$; $p>0.05)$ (Table 2$)$.

Table 2. Treatment.

\begin{tabular}{|c|c|c|c|c|c|}
\hline Registry & CVCA & EURO-ENDO & ICE-PCS & RIEI & $\begin{array}{c}\text { Fernández-Hidalgo } \\
\text { et al. Hospital } \\
\text { Universitari Vall } \\
\text { d'Hebron, Spain }\end{array}$ \\
\hline \multicolumn{6}{|l|}{ Treatment type: } \\
\hline Indication for surgery & $110 / 160(68.8 \%)$ & $2160 / 3115(69.3 \%)$ & & & $318 / 438(72.6 \%)$ \\
\hline Surgery performed & $82 / 160(51.3 \%)$ & $1596 / 3116(51.2 \%)$ & $1335 / 2769(48.0 \%)$ & $422 / 677(62.3 \%) *$ & $174 / 438(39.7 \%)$ * \\
\hline \multicolumn{6}{|l|}{ Type of surgery performed: } \\
\hline Mechanical prosthesis & $5 / 81(3.1 \%)$ & $560 / 1596(35.1 \%) * * *$ & & & $135 / 438(30.8 \%)^{* * *}$ \\
\hline Bioprosthesis & $61 / 81(75.3 \%)$ & $817 / 1596(51.2 \%) * * *$ & & & $36 / 438(8.2 \%) * * *$ \\
\hline Repair & $9 / 81(11.1 \%)$ & $311 / 1596(19.5 \%)$ & & & $3 / 438(0.6 \%)^{* * *}$ \\
\hline $\begin{array}{l}\text { Surgery indicated but not } \\
\text { performed }\end{array}$ & $28 / 160(17.5 \%)$ & $564 / 3115(18.1 \%)$ & & & $144 / 438(32.8 \%) * * *$ \\
\hline $\begin{array}{l}\text { Medical treatment (surgery } \\
\text { not indicated) }\end{array}$ & $50 / 160(31.3 \%)$ & $955 / 3115(30.6 \%)$ & & & $161 / 438(36.8 \%)$ \\
\hline
\end{tabular}

Comparison of the IE treatment in the five studies. Cells markings with asterisks represents the statistical significance levels of the two-sample Pearson's chi-squared tests for the observed proportions. Reported significance levels for pairwise comparison between OLV Hospital and each of the four other registries individually are the following: No asterisk marking given for $p>=0.05,{ }^{*}$ for $p<0.05$ and ${ }^{* * *}$ for $p<0.001$.

Mortality at 30 days was $19.4 \%$, at 90 days $30.6 \%$, at 180 days $34.4 \%$ and at 1 year $37.5 \%$ (Figure 1). 
CVCA: Survival for infective endocarditis 2014-2019, n=160

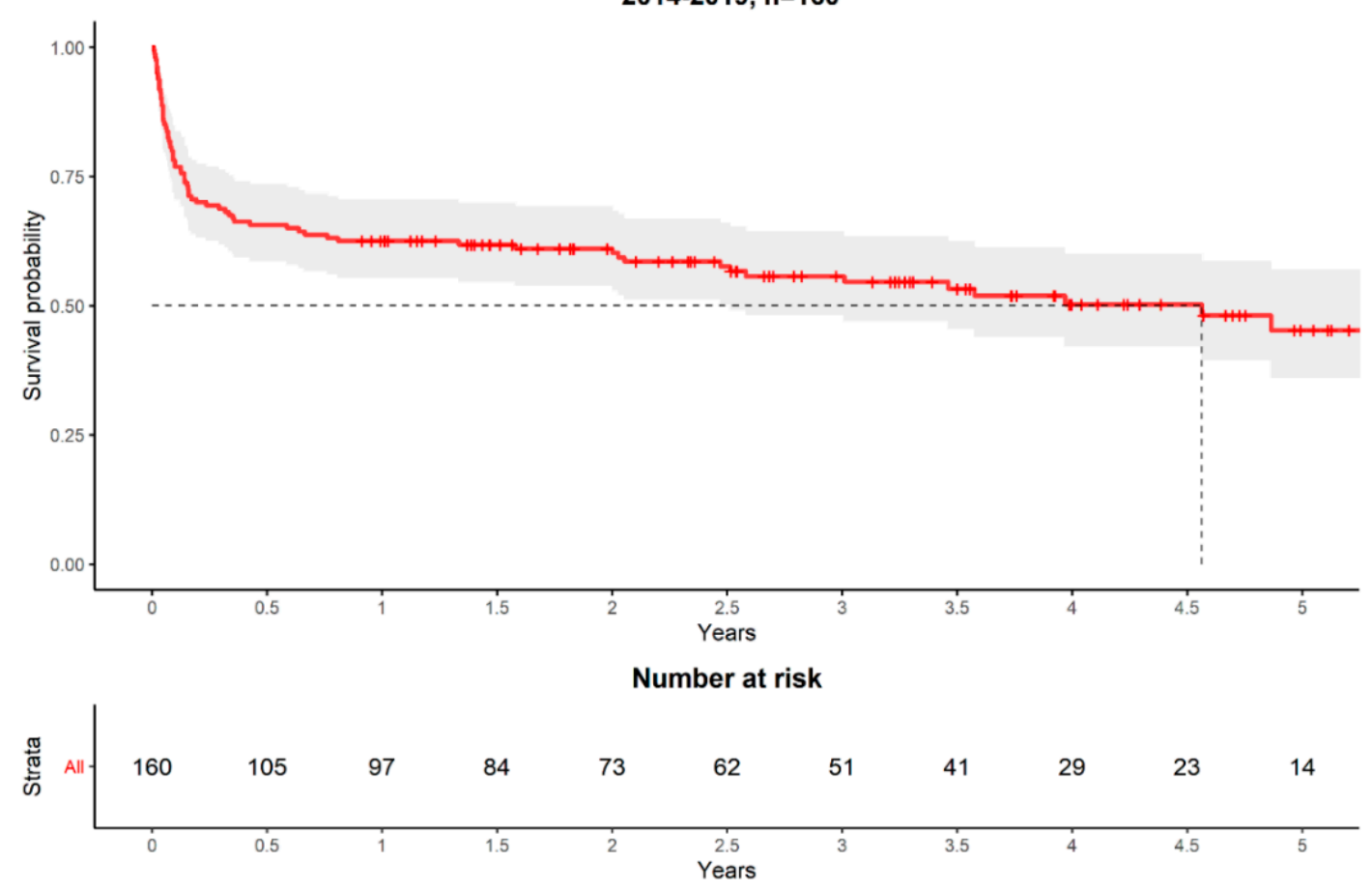

Figure 1. Overall survival curve of the CVCA registry 2014-2019.

In-hospital mortality was non-significantly higher in medically treated patients compared to patients undergoing surgery (Figure 2). The medically treated group was divided into a first group of patients who should have been operated conforming to the guidelines but were not (i.e., considered inoperable by the heart team or refusal by the patient or family) and a second group of patients medically treated conforming to the guidelines. Mortality in the first group was high while mortality in the second group was comparable to surgically treated patients (Figure 2, Table 3).

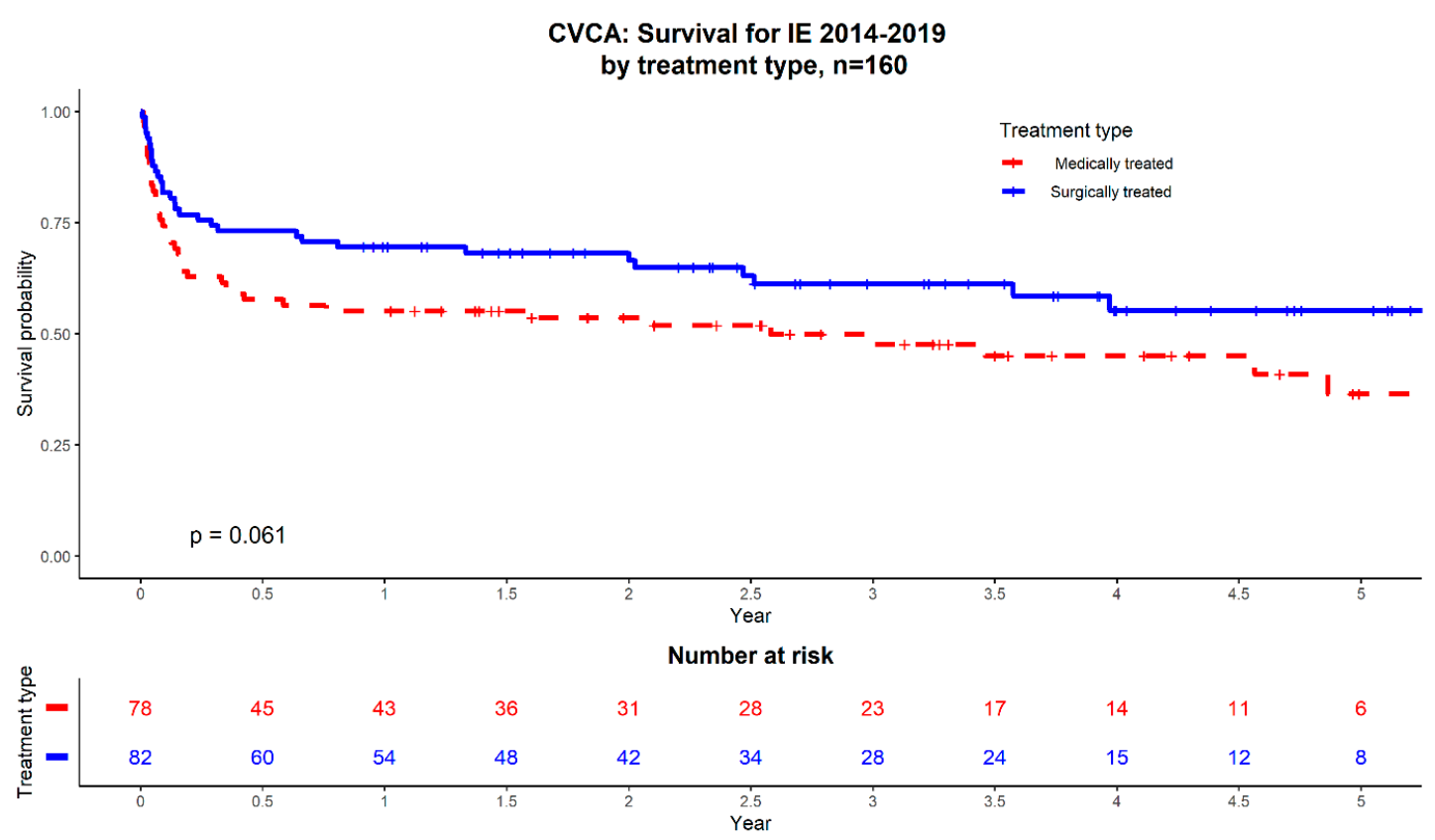

Figure 2. Cont. 
CVCA: Survival for IE 2014-2019

by treatment type, $n=160$

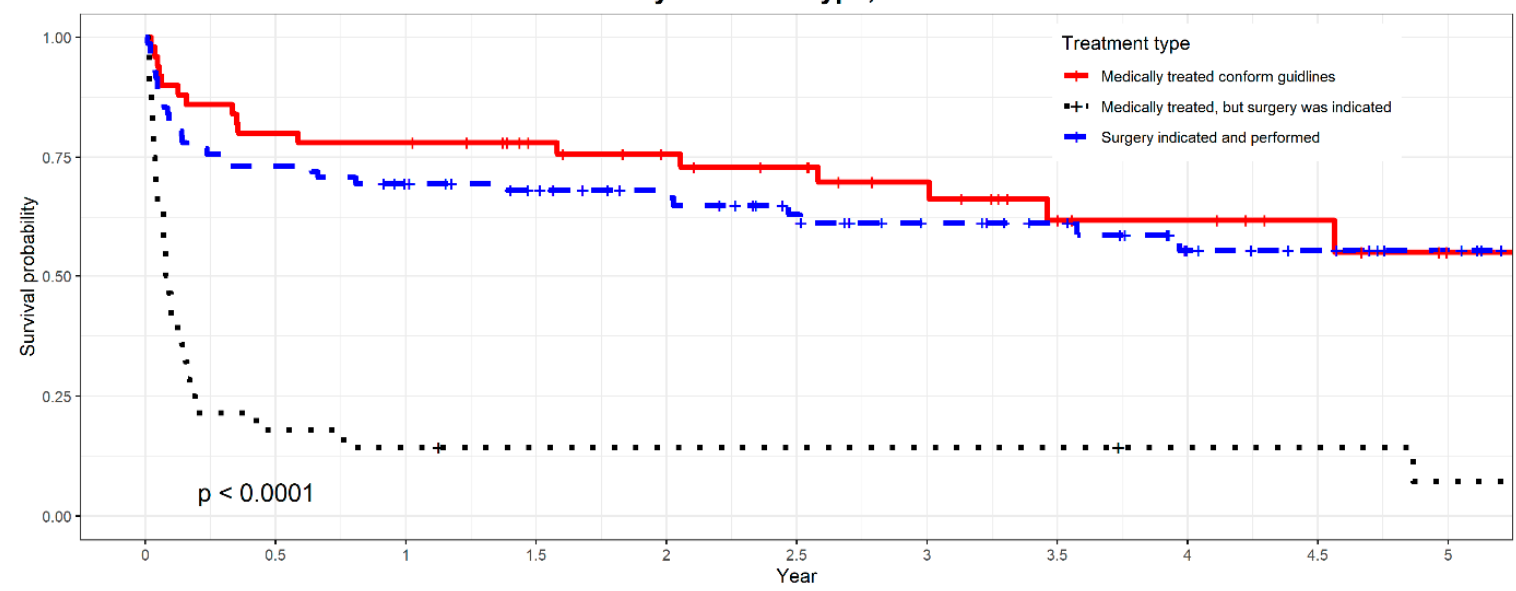

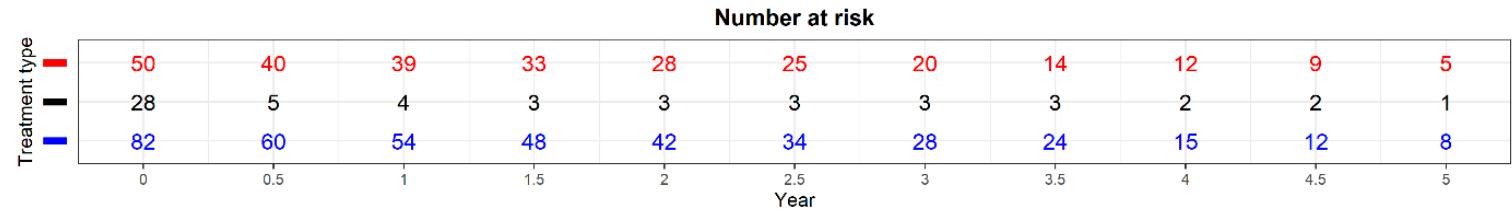

Figure 2. Survival curves of the CVCA registry. Panel 1: Patients grouped according medical or surgical treatment. Panel 2 patients grouped in one surgical and two medical treatment groups. Group I = medically treated patients conforming to the guidelines; Group II = surgically treated patients conforming to the guidelines; Group IIII = medically treated group who should have been operated, conforming to the guidelines, but were not operated (considered inoperable, refusal by the patient...).

Table 3. Risk and outcome.

\begin{tabular}{|c|c|c|c|c|c|}
\hline Registry & OLV Hospital & EURO-ENDO & ICE-PCS & RIEI & $\begin{array}{l}\text { Fernández-Hidalgo et al. Hospital } \\
\text { Universitari Vall d'Hebron, Spain }\end{array}$ \\
\hline \multicolumn{6}{|l|}{ Risk assessments: } \\
\hline Median EuroSCORE & $13.3(6.2-24.0)$ & $5.0(2.0-13.3)^{* * *}$ & & & \\
\hline $\begin{array}{l}\text { Median EuroSCORE when surgery performed } \\
\text { (IQR) }\end{array}$ & $12.5(6.2-22.3)$ & & & & $9(9-12)^{* * *}$ \\
\hline $\begin{array}{l}\text { Median EuroSCORE when surgery indicated } \\
\text { but not performed (IOR) }\end{array}$ & $17.8(9.5-26.7)$ & & & & $11(8-13)$ ** \\
\hline Subjects with definite Modified Duke criteria & 160 & $2610 / 3116(83.8 \%)^{* * *}$ & & & $386 / 438(88.1 \%)^{* * *}$ \\
\hline $\begin{array}{l}\text { Median EuroSCORE prosthetic IE (IQR) } \\
\text { MesCo }\end{array}$ & $19.0(11.1-27.5)$ & $10.9(5.2-24.9)^{* * *}$ & & & \\
\hline Median EuroSCORE native IE (IQR) & $8.6(3.2-18.8)$ & $3.0(1.5-8.0) * * *$ & & & \\
\hline Median EuroSCORE device-related IE (IQR) & $9.0(5.2-16.3)$ & $6.0(2.2-15.0) * *$ & & & \\
\hline \multicolumn{6}{|l|}{$\begin{array}{l}\text { Mortality: } \\
\text { Ment }\end{array}$} \\
\hline In-hospital mortality & $46 / 160(28.7 \%)$ & $532 / 3116(17.1 \%)^{* * *}$ & $490 / 2774(18.0 \%)^{* * *}$ & $93 / 677(13.7 \%)^{* * *}$ & $125 / 677(28.5 \%)$ \\
\hline In-hospital mortality prosthetic IE & $18 / 70(25.7 \%)$ & $187 / 939(19.9 \%)$ & & & \\
\hline In-hospital mortality native IE & $19 / 63(30.2 \%)$ & $286 / 1764(16.2 \%)^{* *}$ & & & \\
\hline In-hospital mortality device-related IE & $9 / 27(30 \%)$ & $47 / 308(15.3 \%)^{*}$ & & & \\
\hline $\begin{array}{l}\text { Cumulative 1-month mortality } \\
\text {. }\end{array}$ & $31 / 160(19.4 \%)$ & & & & \\
\hline Cumulative 3-month mortality & $49 / 160(30.6 \%)$ & & & $(13.8 \%)^{* * *}$ & \\
\hline Cumulative 6-months mortality & $55 / 160(34.4 \%)$ & & & $(15.5 \%)^{* * *}$ & \\
\hline $\begin{array}{l}\text { Cumulative } 1 \text {-year mortality } \\
\text { Con }\end{array}$ & $60 / 160(37.5 \%)$ & & & $(16.7 \%) * * *$ & $150 / 397(37.8 \%)$ \\
\hline
\end{tabular}

Overview of risk assessment and mortality outcome reported in the five studies. Cells markings with asterisks represents the statistical significance levels of the two-sample Pearson's chi-squared tests for the observed proportions and of the one-sample Wilcoxon rank sum tests for the medians. Reported significance levels for pairwise comparison between OLV Hospital and each of the four other registries individually are the following: No asterisks marking given for $p \geq 0.05,{ }^{*}$ for $p<0.05,{ }^{* *}$ for $p<0.01$ and ${ }^{* *}$ for $p<0.001$.

\subsection{Impact of an Infective Endocarditis Heart Team and Prospective Data Collection}

Overall, 92 patients were managed following the recommendations of the IEHT and were compared with 68 controls. Baseline clinical characteristics, aetiology, risk estimation and type of IE were comparable between groups, except for frailty, which was higher in the IEHT group $(5.9 \%$ vs $3.8 \%, p<0.001)$ (Table 4$)$. The observed that length of stay (LOS) tended to be shorter in patients treated following the IEHT approach $(36.1 \pm 25.2$ days vs $44.40 \pm 32$ days, $p=0.0828$ ). In a multivariate analysis, an IEHT decision-making approach was independently associated with a shorter LOS in hospital ( -10.3 days, 95\% CI: -20 to $-0.5 ; p=0.04)$. 
Table 4. Baseline clinical characteristics, aetiology, risk assessment and type of IE: IEHT approach versus standard care.

\begin{tabular}{|c|c|c|c|}
\hline & IEHT Approach & Standard Care & $p$ Value \\
\hline \multicolumn{4}{|l|}{ Baseline characteristics } \\
\hline Age & 6/69.5 (sd: 13.3) & 71.0 (sd: 11.8) & 0.4710 \\
\hline Gender (male) & $66 / 92(71.7 \%)$ & $54 / 68(79.4 \%)$ & 0.3558 \\
\hline Diabetes & $33 / 92(35.9 \%)$ & $20 / 68(29.4 \%)$ & 0.4914 \\
\hline COPD & $16 / 92(17.6 \%)$ & $12 / 68(17.4 \%)$ & 0.9999 \\
\hline GFR & 52.1 (sd: 28.7) & 54.1 (sd: 25.7$)$ & 0.6393 \\
\hline Previous cardiac surgery & $44 / 92(47.8 \%)$ & $36 / 68(52.9 \%)$ & 0.6314 \\
\hline Previous coronary artery disease & $25 / 92(27.2 \%)$ & $24 / 68(35.3 \%)$ & 0.3534 \\
\hline Stroke & $8 / 92(8.7 \%)$ & $6 / 68(8.8 \%)$ & 0.9999 \\
\hline Peripheral arterial disease & $13 / 92(14.1 \%)$ & $15 / 68(22.1 \%)$ & 0.2738 \\
\hline LVEF $<50 \%$ & $23 / 92(25.0 \%)$ & $10 / 68(14.7 \%)$ & 0.1835 \\
\hline Degenerative Valve Disease & $54 / 92(58.7 \%)$ & $35 / 68(51.5 \%)$ & 0.4542 \\
\hline Previous endocarditis & $9 / 92(9.8 \%)$ & $6 / 68(8.8 \%)$ & 0.9999 \\
\hline Cancer & $14 / 92(19.1 \%)$ & $13 / 68(15.2 \%)$ & 0.6616 \\
\hline \multicolumn{4}{|l|}{ Aetiology } \\
\hline Streptococcus viridans & $8 / 92(8.7 \%)$ & $9 / 68(13.2 \%)$ & 0.5082 \\
\hline Staphylococcus aureus & $27 / 92(29.4 \%)$ & $20 / 68(29.3 \%)$ & 0.9999 \\
\hline Enterococcus & $18 / 92(19.6 \%)$ & $19 / 68(27.9 \%)$ & 0.2925 \\
\hline \multicolumn{4}{|l|}{ Risk Assessment } \\
\hline Charlson index (not age related) & 82.7 (sd: 21.4) & 81.1 (sd: 27.3) & 0.6745 \\
\hline Frailty score & $5.6(\mathrm{sd}: 1.8)$ & 3.8 (sd: 2.5$)$ & 0.0001 \\
\hline Euroscore II & 16.7 (sd: 12.6$)$ & $17.4(\mathrm{sd}: 16.7)$ & 0.7535 \\
\hline KATZ score & 3.2 (sd: 2.1$)$ & 3.4 (sd: 2.3$)$ & 0.6216 \\
\hline Global Risk score & 1.8 (sd: 0.8$)$ & 2.1 (sd: 0.9) & 0.0879 \\
\hline \multicolumn{4}{|l|}{ IE Type: } \\
\hline Prosthetic & $38 / 92(41.3 \%)$ & $32 / 68(47.1 \%)$ & \\
\hline Native & $34 / 92(37.0 \%)$ & $29 / 68(42.6 \%)$ & 0.1610 \\
\hline Device-related & $20 / 92(21.7 \%)$ & $7 / 68(10.3 \%)$ & \\
\hline
\end{tabular}

Overview of basic characteristics, demography, cardiovascular disease history, risk factors and comorbidities before propensity score matching: IEHT approach versus standard care.

Table 5 shows unadjusted and adjusted mortality after propensity score, matching between patients treated under IEHT and controls. There was no difference in in-hospital mortality. However, after propensity matching, mortality at 6 months and 1 year tended to be lower in patients managed by the IEHT ( $23.5 \%$ IEHT vs $36.8 \%$ controls, $p=0.0926$ and $26.5 \%$ IEHT vs. $41.2 \%$ controls, $p=0.0699$, respectively). Figure 3 shows survival curves of patients with definite IE managed by the IEHT and controls.

Table 5. Outcome IEHT approach versus standard care.

\begin{tabular}{cccc}
\hline & IEHT Approach & Standard Care & $p$ Value \\
\hline Unadjusted mortality & & & \\
In-hospital mortality & $28.3 \%$ & $29.4 \%$ & 0.8737 \\
30 days mortality & $20.7 \%$ & $20.7 \%$ & 0.8104 \\
180 days mortality & $32.6 \%$ & $36.8 \%$ & 0.5843 \\
1 year mortality & $34.8 \%$ & $41.2 \%$ & 0.4089 \\
After propensity score matching & & & \\
In-hospital mortality & $17.7 \%$ & $29.4 \%$ & 0.1058 \\
30 days mortality & $14.7 \%$ & $19.1 \%$ & 0.4926 \\
180 days mortality & $23.5 \%$ & $36.8 \%$ & 0.0926 \\
1 year mortality & $26.5 \%$ & $41.2 \%$ & 0.0699
\end{tabular}

Comparison of mortality data In-hospital, after 30 days, after 180 days, after 1 year between IEHT approach and standard care unadjusted and after propensity score matching. 

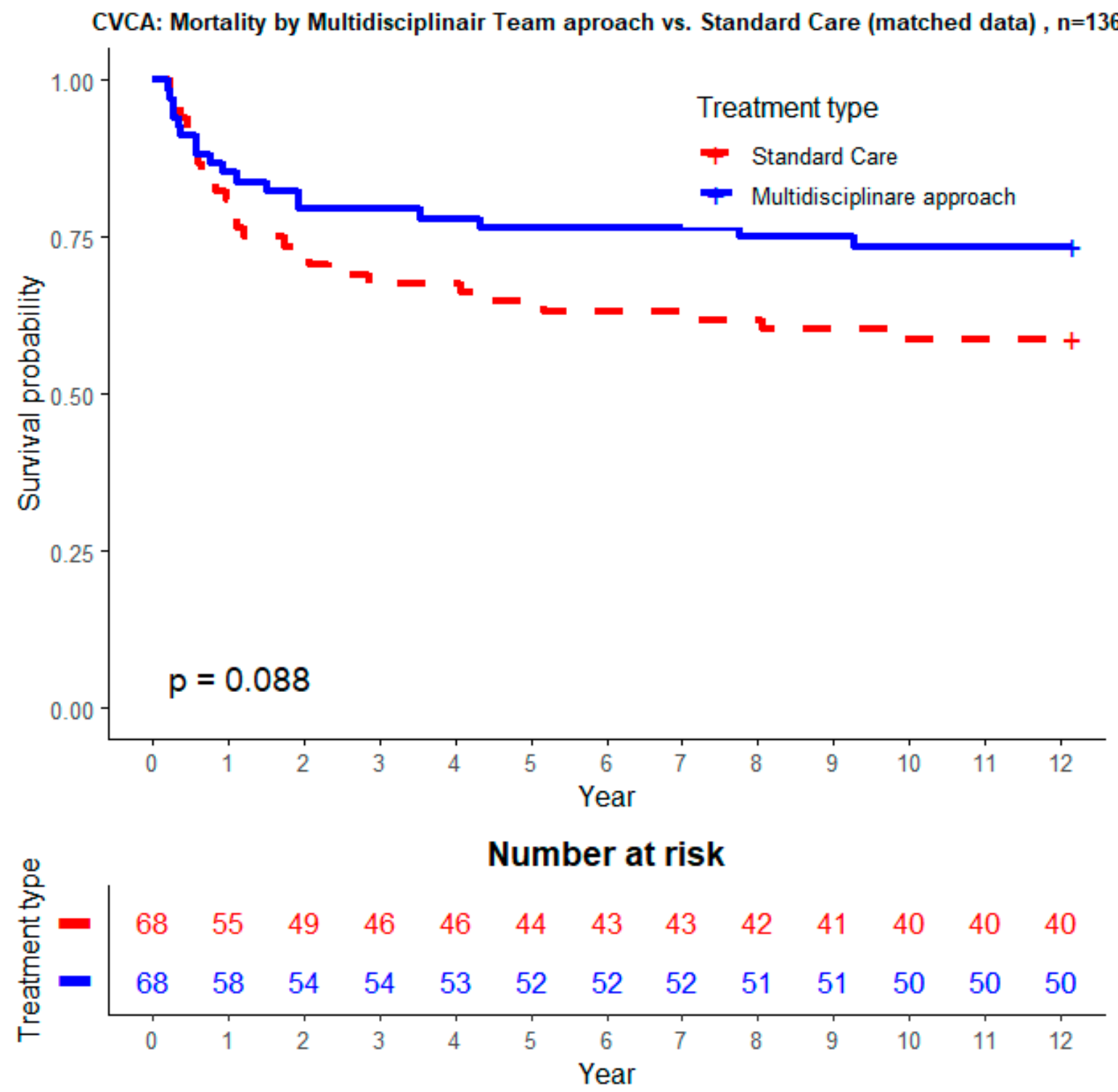

Figure 3. Survival curves of patients entered in the database during 2015 without IEHT compared to the survival curve of patients entered in 2019, while the IEHT was well introduced.

\section{Discussion}

From our prospective in-hospital registry of IE, we can conclude that compared with contemporary literature, our population with IE: 1) is at higher risk, has more enterococcus IE probably related to older age, has more PVE and CDRIE, is detected with similar sensitivity compared to other centres by echo and PET, is as frequently operated, has a 30-day and 1-year mortality comparable with mortality rates mentioned in current literature. Mortality was high in those patients treated medically, although surgery was theoretically indicated. 2) The introduction of IEHT led to a reduction in LOS with a trend towards reduction in mortality. These results demonstrate that an in-hospital registry for IE and a multidisciplinary approach can be used as a management tool to evaluate and improve the quality of care of patients with IE.

Benchmarking medical management of every disease starts with precise characterization of the population studied. These characteristics of patients with IE can vary depending on several hospital and environmental aspects. Comparison of our population with the most recent published registries illustrate that our patients were older, had more frequent diabetes, COPD, chronic kidney disease and prosthetic valves or electronic devices [1,5,7-9]. 
This resulted in a high-risk population documented by high-risk scores (i.e., STS, Euroscore II, Charlson co-morbidity, Katz score, frailty and global risk score). All the patient characteristics associated with poor outcome mentioned in the latest guidelines were more frequently present in the CVCA registry: older age, prosthetic valve IE, diabetes mellitus, comorbidity (e.g., frailty, renal, or pulmonary disease) [2]. These high-risk characteristics must be acknowledged in the comparison of outcome with other registries.

The microbiological findings of our IE population are mostly in line with current literature [14-17]. In developed countries, IE patients are older and IE cases are more frequently related to health-care facilities. Prosthetic valves and CIED devices have replaced rheumatic disease as the main risk factor for IE [2,14-16]. In parallel, staphylococcus has replaced streptococcus as the most frequently isolated pathogen.

Staphylococcus aureus is also in CVCA, the most frequently encountered organism responsible for $37.5 \%$ of IE, followed by Streptococcus IE (24.4\%). Enterococcus, however, is almost as frequently present as Streptococcus species (23.1\%). This is higher compared to all other registries. This can probably be explained by the older age of the CVCA registry and is illustrated by the frequent finding of a digestive entrance place (multiple polyps and cancer). In CVCA registry, IE was frequently health care related (40\%) with an important representation of non-nosocomial health care related IE that can be explained by the old age of this population living frequently in residential care centres.

PVE (43.8\%) and CDRIE (16.9\%) represent a larger group of IE patients in the CVCA registry compared to other current registries [1,5,7-9]. This can be explained by the fact that within a developed country, the hospital is a referral centre for valvular heart disease. Patients that were operated on (valve surgery) or had device implants in the hospital are also referred to the CVCA when complications occur. This aspect must be considered when evaluating the outcome of IE patients since mortality is higher in PVE and CDRIE compared to native valve IE.

TTE was less often performed in the CVCA registry, which is due to the fact that TTE is often already performed by the referral hospital and exams are available when the patients arrive in the CVCA. TEE and PET-CT were frequently performed and the more frequent use of PET-CT in the CVCA registry results probably also in the less frequently performed MDCT. The diagnostic yield of these imaging techniques was comparable with other registries. Since not one of these techniques is the holy grail, multi-modality imaging is key in the diagnosis of IE [18].

The CVCA registry counts less culture negative IE (3.8\%), illustrating the high performance of microbiological detection of IE. The microbiological team is active in the hospital, working with the different departments when blood cultures are positive, while sensible physicians actively perform complementary imaging techniques or perform supplementary blood cultures in patients with unexplained infections.

Complications are similar in CVCA and other current registries [1,5,7-9]. Surgery was performed in $82 / 160(51.3 \%)$ patients in the CVCA registry, also comparable with the other registries. The proportion of patients who needed surgery but in whom surgery was not performed $(18.1 \%)$ is also comparable. Less mechanical valves are implanted in the CVCA registry, probably linked to older age. Despite this older population, valve repair was performed as frequently as in the recent EURO-ENDO registry, illustrating the efforts of the surgical department to repair valves in IE when possible.

Mortality of IE in CVCA in-hospital was $28.7 \%$, at 30 days $19.4 \%$, at 90 days $30.6 \%$, at 180 days $34.4 \%$ and at 1 year $37.5 \%$. These results are consistent with current literature. Inhospital mortality is difficult to compare between studies and registries since it depends on the regional health care organization (early versus late discharge; early versus late referral to other care facilities). Therefore, 30-day and 1-year mortality should also be used as reliable metrics. The 30 -day mortality of $19.4 \%$ was comparable, with most publications reporting mortality rates of $10-30 \%[4,19]$. A 1-year mortality of $37.5 \%$ is also comparable with literature, reporting rates of $21-40 \%[5,8,9,18]$. CVCA mortality rate cannot be compared with the EURO-ENDO registry since only in-hospital mortality was reported (17.1\%). The 
1-month mortality is missing in the other registries but the 1-year mortality of the RIEI registry was $16.7 \%$ and $37.8 \%$ in the study of Hidalgo et al $[8,9]$. Comparison of outcomes of IE between prospective studies and registries remains difficult, but considering the high-risk profile of the CVCA population and the inclusion of only definite IE cases (EUROENDO [1] and Hidalgo et al. [9] included possible and definite IE), outcome in the CVCA registry compares favourably with other data.

Patients treated medically or surgically following the guidelines have the same favourable outcome. Contrarily, patients treated medically, although the guidelines indicate surgical treatment, have a dramatic high mortality. This finding is consistent with the EURO-ENDO registry [1].

Linked to the high mortality of IE and the multi-system involvement in most patients with IE, current guidelines encourage an organized multidisciplinary approach for these patients, including cardiologists, cardiac surgeons, cardiac anaesthetists, neurologists, microbiologists and intensive care physicians and the use of clinical pathways integrating the existing guidelines $[2,19,20]$. Although the heart team has already functioned many years in the hospital, we organized an IEHT in 2017, implementing a multidisciplinary approach with a focus on early recognition with acute close monitoring in the cardiac intensive care unit, early multidisciplinary decision-making using current guidelines and close follow-up in the heart team during the course of the hospitalization. The prospective registry enables us to compare the current outcome of patients with IE before the introduction of the IEHT (year 2014-2016) with the period with IEHT (2017-2019). We found an important reduction of the LOS of more than 8 days. An IEHT decision-making approach was independently associated with a shorter length of stay in-hospital. This can be explained by the early decision making within the IEHT. We observed a tendency towards a better outcome with IEHT (1-year mortality decreases from $41.2 \%$ to $34.8 \%$ ) despite a higher frailty in the IEHT group. After propensity score matching, 1-year mortality decreased from $41.2 \%$ before IEHT to $26.5 \%$ with IEHT ( $p=0.0699)$, illustrating, besides the impact on the LOS, the potential benefit of an early multidisciplinary approach on outcomes.

Future perspectives: Considering the great proportion of PVE and CDRIE in our CVCA registry, prophylactic measurements to prevent this deadly disease should be encouraged. Supplementary tools to instruct our patients with prosthetic valves and electronic devices to follow rigorously prophylactic measures against IE will be introduced. The multidisciplinary approach will be continued within the IEHT with a special attention to the group of patients in whom surgery would be denied in contradiction with the guidelines. This will be challenging due to the older age and the frailty of our population. Finally, patients will be followed in the valve clinic after hospital discharge, knowing the still high mortality in this population.

\section{Limitations}

The major limitation of this single-centre study is the low number of patients. However, a complete dataset of current prospective obtained data in 160 patients with long-term follow-up enhances the knowledge in the domain of IE in which data are still scarce.

\section{Conclusions}

We can conclude from our CVCA registry that in-hospital prospective registration of data in IE patients permits to characterize the particular IE patient population of the hospital, which is a high-risk population in CVCA and which can differ significantly from other published registries. These differences can have a major impact on the interpretation of the outcome. In-hospital prospective registration of IE patients is the only way to monitor the effect of interventions to lower mortality in this disease. Implementation of IEHT resulted in an important decrease in the LOS with a non-significant trend for lower mortality. 
Author Contributions: Conceptualization: G.V.C., M.P., D.S., S.W., H.D.R., H.D.B. and C.C.; data curation: M.B., R.N., Z.B., M.A., H.D.B., K.V.V., F.V.P., I.D., B.S. and F.C.; formal analysis: G.V.C., M.B., D.S. and C.C.; investigation: G.V.C., M.P., R.N. and C.C.; methodology: G.V.C., H.D.B., K.V.V. and C.C.; software, M.B.; validation: C.C.; writing-original draft: G.V.C., E.W., J.S., D.S. and C.C. All authors take responsibility for all aspects of the reliability and freedom from bias of the data presented and their discussed interpretation. All authors have read and agreed to the published version of the manuscript.

Funding: This research did not receive any specific grant from funding agencies in the public, commercial, or not-for-profit sectors.

Institutional Review Board Statement: The study was conducted in accordance with the Declaration of Helsinki, and the protocol was approved by the Ethics Committee of OLV Aalst (Project identification code 2020/064).

Informed Consent Statement: All subjects gave their oral informed consent for inclusion before they participated in the study.

Data Availability Statement: The data underlying this article are available in the article.

Conflicts of Interest: The authors declare no conflict of interest.

\section{Appendix A}

Table A1. Patient characteristics (CVCA and other registries).

\begin{tabular}{|c|c|c|c|c|c|}
\hline Registry & CVCA & EURO-ENDO & ICE-PCS & RIEI & $\begin{array}{l}\text { Fernández-Hidalgo et al. Hospital } \\
\text { Universitari Vall d'Hebron, Spain }\end{array}$ \\
\hline $\mathrm{N}$ hospitals & 1 & 156 & 58 & 17 & 1 \\
\hline $\mathrm{N}$ countries & 1 & 40 & 25 & 1 & 1 \\
\hline Data collection period & 2014-2019 & January 2016-March 2018 & 2000-2005 & 2007-2010 & 2000-2011 \\
\hline Cases included & Definite IE & $\begin{array}{l}\text { Possible with treatment \& } \\
\text { Definite IE }\end{array}$ & Definite IE & Definite IE & Left-sided possible and definite IE \\
\hline \multicolumn{6}{|l|}{ Demography: } \\
\hline $\mathrm{N}$ & 160 & 3116 & 2781 & 677 & 438 \\
\hline Median age in years (IQR) & $72.50(62.75 \pm 80.00)$ & $63.0(46.0-73.0)^{* * *}$ & $57.9(43.2-71.8)^{* * *}$ & $65.34(49.60-74.39) * * *$ & $66.4(51.8-74.9) * * *$ \\
\hline Age $\geq 65$ years & $112 / 160(70 \%)$ & $1443 / 3116(46.3 \%)^{* * *}$ & & & \\
\hline Age $\geq 80$ years & $44 / 160(27.5 \%)$ & $375 / 3116(12.0 \%)^{* * *}$ & & $60 / 677(8.7 \%)^{* * *}$ & \\
\hline \multirow{2}{*}{\multicolumn{6}{|c|}{ 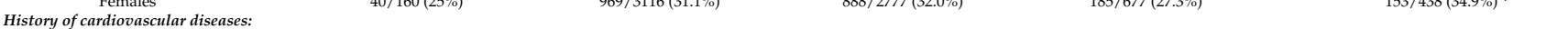 }} \\
\hline & & & & & \\
\hline Heart failure & $33 / 160(20.6 \%)$ & $662 / 2840(23.3 \%)$ & & & \\
\hline Congenital disease & $13 / 160(8.1 \%)$ & $365 / 3114(11.7 \%)$ & $311 / 2656(12.0 \%)$ & $39 / 677(5.8 \%)$ & \\
\hline Ischaemic heart disease & $49 / 160(30.6 \%)$ & $622 / 2897(21.5 \%)^{* *}$ & & $95 / 677(14.0 \%)^{* * *}$ & \\
\hline Peripheral arterial disease & $28 / 160(17.5 \%)$ & & & & \\
\hline Previous endocarditis & $15 / 160(9.4 \%)$ & $274 / 3116(8.8 \%)$ & $222 / 2780(8.0 \%)$ & & \\
\hline Intra-cardiac device & $44 / 160(27.6 \%)$ & $537 / 3116(17.2 \%)^{* *}$ & & $122 / 677(18.0 \%)^{* *}$ & \\
\hline \multirow{2}{*}{\multicolumn{6}{|c|}{ Risk factors and comorbidities: }} \\
\hline & & & & & \\
\hline Diabetes & $53 / 160(33.1 \%)$ & & $447 / 2764(16.0 \%) * * *$ & $116 / 677(17.1 \%)^{* * *}$ & $99 / 438(22.6 \%)^{*}$ \\
\hline Previous stroke/TIA & $14 / 160(8.8 \%)$ & $340 / 2860(11.9 \%)$ & & $35 / 677 \mathrm{a}(5.2 \%)$ & \\
\hline $\mathrm{COPD} / \mathrm{asthma}$ & $28 / 160(17.5 \%)$ & $318 / 3111(10.2 \%)^{* *}$ & & $65 / 677(9.6 \%)^{* *}$ & \\
\hline Chronic renal failure & $44 / 160(27.5 \%)$ & $553 / 3113(17.8 \%) * *$ & & $85 / 677(12.6 \%)^{* * *}$ & \\
\hline Dialysis & $19 / 160(11.9 \%)$ & $163 / 3113(5.2 \%)^{* * *}$ & $220 / 2777(8.0 \%)$ & & $22 / 438(5.0 \%)^{* *}$ \\
\hline HIV & $2 / 160(1.2 \%)$ & $31 / 3038(1.0 \%)$ & $58 / 2748(2.0 \%)$ & $40 / 677(5.9 \%)^{*}$ & $15 / 438(3.4 \%)$ \\
\hline Chronic liver disease & $13 / 160(8.2 \%)$ & & & $64 / 677(9.5 \%)$ & \\
\hline Cancer & $27 / 160(16.9 \%)$ & $361 / 3088(11.7 \%)$ & $230 / 2772(8.0 \%)^{* * *}$ & $66 / 677(9.8 \%)^{*}$ & $56 / 438(13.5 \%)$ \\
\hline Intravenous drug dependency & $3 / 160(1.9 \%)$ & $212 / 3067(6.9 \%)^{*}$ & $268 / 2746(10.0 \%)^{* *}$ & $61 / 677(9.0 \%)^{* *}$ & $12 / 438(2.7 \%)$ \\
\hline Intravenous catheter & $12 / 160(7.5 \%)$ & $250 / 3104(8.1 \%)$ & $244 / 2763(9.0 \%)$ & $71 / 677(10.5 \%)$ & \\
\hline Invasive procedure within 60 days & $43 / 160(26.9 \%)$ & & $690 / 2581(27.0 \%)$ & $171 / 677(25.3 \%)$ & \\
\hline
\end{tabular}

Overview of basic study specifications, demography, cardiovascular disease history, risk factors and comorbidities in the five samples. Cell markings with asterisks represent the statistical significance levels of the two-sample Pearson's chi-squared tests for the observed proportions and of the one-sample Wilcoxon rank sum tests for the medians. Reported significance levels for pairwise comparison between OLV Hospital and each of the four other registries individually are the following: no asterisks marking given for $p>=0.05,{ }^{*}$ for $p<0.05$, ** for $p<0.01$ and ${ }^{* * *}$ for $p<0.001$.

Table A2. Clinical presentation.

\begin{tabular}{|c|c|c|c|c|c|}
\hline Registry & CVCA & EURO-ENDO & ICE-PCS & RIEI & $\begin{array}{l}\text { Fernández-Hidalgo et al. Hospital } \\
\text { Universitari Vall d'Hebron, Spain }\end{array}$ \\
\hline \multicolumn{6}{|l|}{ Clinical onset and assessment: } \\
\hline First sign to admission $<1$ month & $141 / 160(88.1 \%)$ & & $2088 / 2711(77.0 \%)$ & $340 / 677(50.2 \%)^{* * *}$ & \\
\hline Transferred from other centres & $45 / 160(28.1 \%)$ & & & $305 / 677(45.0 \%)^{* * *}$ & $170 / 438(38.8 \%)^{*}$ \\
\hline Fever & $95 / 160(59.4 \%)$ & $2383 / 3068(77.7 \%)^{* * * *}$ & $2322 / 2428(96.0 \%)^{* * *}$ & $568 / 677(83.9 \%)^{* * *}$ & \\
\hline Increased C-reactive protein & $159 / 160(99.4 \%)$ & & $1632 / 2650(62.0 \%)^{* * *}$ & $566 / 877(83.6 \%)^{* * *}$ & \\
\hline New murmur or worsening old murmur & $40 / 160(25 \%)$ & $2008 / 3112(64.5 \%) * * *$ & $1970 / 2781(70.8 \%)^{* * *}$ & $358 / 677(52.9 \%)^{* * *}$ & \\
\hline Haematuria & $69 / 160(43.1 \%)$ & & $666 / 2587(26.0 \%)^{* * * *}$ & $97 / 677(14.3 \%)^{* * * *}$ & \\
\hline Creatinine $>2$ & $45 / 160(28.1 \%)$ & & & $75 / 677(11.1 \%)^{* * *}$ & \\
\hline Osler nodes & $1 / 160(0.6 \%)$ & $60 / 3116(1.9 \%)$ & $77 / 2648(3.0 \%)$ & $26 / 677(3.8 \%)$ & \\
\hline Splint haemorrhage & $1 / 160(0.6 \%)$ & & $213 / 2655(8.0 \%) * *$ & $9 / 677(1.3 \%)$ & \\
\hline Janeway lesion & $2 / 160(1.2 \%)$ & $109 / 3116(3.5 \%)$ & $123 / 2650(5.0 \%)$ & $6 / 677(0.9 \%)$ & \\
\hline Conjunctival haemorrhage & $2 / 160(1.2 \%)$ & & $122 / 2655(5.0 \%)$ & $6 / 677(0.9 \%)$ & \\
\hline Roth spots & $2 / 160(1.2 \%)$ & $44 / 3052(1.4 \%)$ & $50 / 2649(1.89 \%)$ & & \\
\hline
\end{tabular}

Summary of the clinical onset and assessments reported in the five studies. Cell markings with asterisks represent the statistical significance levels of the two-sample Pearson's chi-squared tests for the observed proportions. Reported significance levels for pairwise comparison between OLV Hospital and each of the four other registries individually are the following: no asterisks marking given for $p>=0.05$, ${ }^{*}$ for $p<0.05,{ }^{* *}$ for $p<0.01$ and ${ }^{* * *}$ for $p<0.001$. 
Table A3. Type and etiology of IE.

\begin{tabular}{|c|c|c|c|c|c|}
\hline Registry & CVCA & EURO-ENDO & ICE-PCS & RIEI & $\begin{array}{l}\text { Fernández-Hidalgo et al. Hospital } \\
\text { Universitari Vall d'Hebron, Spain }\end{array}$ \\
\hline \multicolumn{6}{|l|}{ Type IE: } \\
\hline Native valve & $63 / 160(39.4 \%)$ & $1764 / 3116(56.6 \%)^{* * * *}$ & $1901 / 2636(72.0 \%)^{* * * *}$ & $445 / 677(65.7 \%) * * *$ & $337 / 485(76.9 \%)^{* * *}$ \\
\hline Prosthetic valve & $70 / 160(43.8 \%)$ & $939 / 3116(30.1 \%)^{* * *}$ & $563 / 2636(21.0 \%)^{* * *}$ & $128 / 677(18.9 \%)^{* * *}$ & $101 / 485(23.1 \%)^{* * * *}$ \\
\hline Intra-cardiac device related & $27 / 160(16.9 \%)$ & $308 / 3116(9.9 \%)^{* *}$ & $172 / 2636(7.0 \%)^{* * *}$ & $94 / 677(13.9 \%)$ & \\
\hline Aetiology: & & & & & \\
\hline Positive blood culture & $154 / 160(96.3 \%)$ & $2461 / 3116(79.0 \%)^{* * *}$ & & $492 / 677(72.7 \%)^{* * *}$ & \\
\hline Streptococci & $39 / 160(24.4 \%)$ & & & & $163 / 438(37.2 \%)^{* *}$ \\
\hline Viridans streptococci & $17 / 160(10.6 \%)$ & $304 / 2461(12.4 \%)$ & $483 / 2781(17.0 \%)^{*}$ & $73 / 677(14.8 \%)$ & $103 / 438(23.5 \%)^{* * *}$ \\
\hline Streptococcus bovis complex & $12 / 160(7.5 \%)$ & & $165 / 2781(6.0 \%)$ & $57 / 677(11.6 \%)$ & $33 / 438(7.5 \%)$ \\
\hline Streptococcus agalactiae & $3 / 160(1.9 \%)$ & & & & \\
\hline Pneumococcus & $5 / 160(3.1 \%)$ & & & & \\
\hline Other streptococci & $1 / 160(0.6 \%)$ & & $162 / 2781(6.0 \%) * *$ & & \\
\hline Staphylococci & $60 / 160(37.5 \%)$ & $1085 / 2461(44.1 \%)$ & & & $143 / 438(32.6 \%)$ \\
\hline Staphylococcus aureus & $47 / 160(29.4 \%)$ & $772 / 2461(31.3 \%)$ & $869 / 2781(31.0 \%)$ & $133 / 677(27.0 \%)^{* *}$ & $99 / 438(22.6 \%)$ \\
\hline Methicillin-resistant S. aureus & $0 / 160(0 \%)$ & $177 / 2461(7.2 \%) * * *$ & & $37 / 677(5.4 \%)^{* * *}$ & $23 / 438(5.3 \%)^{* *}$ \\
\hline Coagulase-negative staphylococci & $13 / 160(8.1 \%)$ & $313 / 2461(12.7 \%)$ & $304 / 2781(11.0 \%)$ & $106 / 677(21.6 \%)^{*}$ & $44 / 438(10.0 \%)$ \\
\hline Enterococci & $37 / 160(23.1 \%)$ & $390 / 2461(15.8 \%)^{*}$ & $283 / 2781(10.0 \%)^{* * *}$ & $75 / 677(15.1 \%)^{* * * *}$ & $59 / 438(13.5 \%)^{* *}$ \\
\hline Gram-negative rods (GNR) & $3 / 160(1.9 \%)$ & $86 / 2461(3.5 \%)$ & & & $19 / 438(4.3 \%)$ \\
\hline HACEK group & $1 / 160(0.6 \%)$ & & $44 / 2781(2.0 \%)$ & $6 / 677(1.2 \%)$ & $9 / 438(2.1 \%)$ \\
\hline Fungi/yeast & $1 / 160(0.6 \%)$ & & $45 / 2781(2.0 \%)$ & & \\
\hline Polymicrobial & $4 / 160(2.5 \%)$ & & $28 / 2781(1.0 \%)$ & & \\
\hline Culture negative & $6 / 160(3.8 \%)$ & & $310 / 2781(11.1 \%)^{* *}$ & & \\
\hline
\end{tabular}

Overview of the infective endocarditis type and etiology reported in the five studies. Cell markings with asterisks represent the statistical significance levels of the two-sample Pearson's chi-squared tests for the observed proportions. Reported significance levels for pairwise comparison between OLV Hospital and each of the five other registries individually are the following: No asterisk marking given for $p>=0.05,{ }^{*}$ for $p<0.05,{ }^{* *}$ for $p<0.01$ and ${ }^{* * *}$ for $p<0.001$.

Table A4. Risk scores in CVCA registry.

\begin{tabular}{|c|c|c|c|c|c|}
\hline & $\begin{array}{c}\text { Prosthetic IE } \\
\quad n=70\end{array}$ & $\begin{array}{l}\text { Native IE } \\
\quad n=63\end{array}$ & $\begin{array}{l}\text { Cardiac Device Related IE } \\
\qquad n=27\end{array}$ & $\begin{array}{c}\text { Significance } \\
\text { Level of } p \text {-Value }\end{array}$ & $\begin{array}{l}\text { Overall } \\
n=160\end{array}$ \\
\hline Median EuroSCORE (IQR) & $19.0(11.1-27.5)$ & $8.6(3.2-18.8)$ & $9.0(5.2-16.3)$ & $* * *$ & $13.3(6.2-24.0)$ \\
\hline $\begin{array}{l}\text { Median STS score (only calculated for } \\
\text { aortic or mitral valve surgeries) }\end{array}$ & $8.6(5.7-17.8)$ & $6.6(3.8-13.5)$ & $6.8(4.8-24.6)$ & & $7.5(4.2-15.9)$ \\
\hline Global risk score $>=2$ & $49(70.0 \%)$ & $44(69.8 \%)$ & $21(77.8 \%)$ & & $114(71.3 \%)$ \\
\hline $\begin{array}{l}\text { Median Charlson comorbidity } \\
\text { index-not age related (IQR) }\end{array}$ & $96.0(90.2-98.3)$ & $90.2(77.5-98.3)$ & $90.2(53.4-95.9)$ & * & $90.2(77.4-98.3)$ \\
\hline Median Katz score (IQR) & $4.0(2.0-5.0)$ & $3.0(1.0-5.0)$ & $4.0(2.0-5.8)$ & & $3.0(2.0-5.0)$ \\
\hline Median frailty score (IQR) & $4.5(3.0-6.0)$ & $6.0(4.0-7.0)$ & $5.0(4.0-6.0)$ & & $5.0(3.0-7.0)$ \\
\hline
\end{tabular}

Risk score in the different groups of IE. Median values are shown. No asterisks marking given for $p>=0.05,{ }^{*}$ for $p<0.05$ and ${ }^{* * *}$ for $p<0.001$.

Table A5. Entrance site and acquisition.

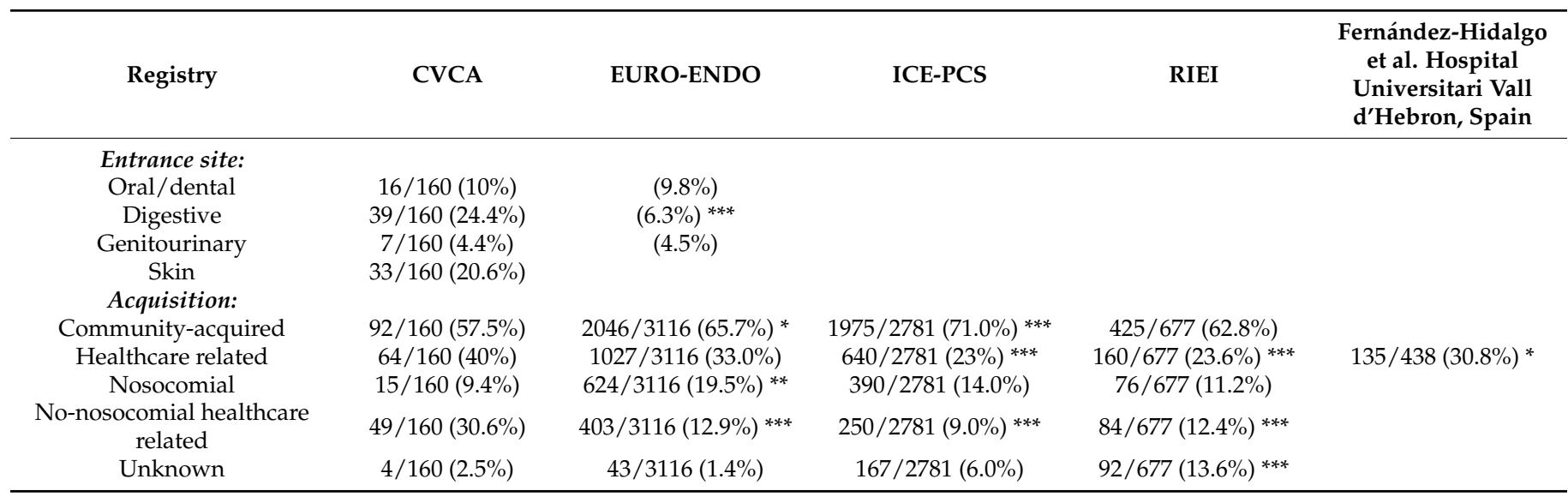

Comparison of the IE entrance site and acquisition reported in the five studies. Cell markings with asterisks represent the statistical significance levels of the two-sample Pearson's chi-squared tests for the observed proportions. Reported significance levels for pairwise comparison between CVCA and other registries. No asterisks marking given for $p>=0.05,{ }^{*}$ for $p<0.05,{ }^{* *}$ for $p<0.01$ and ${ }^{* * *}$ for $p<0.001$. 
Table A6. Diagnostic Imaging.

\begin{tabular}{ccccc}
\hline Registry & CVCA & EURO-ENDO & ICE-PCS & $\begin{array}{c}\text { Fernández-Hidalgo } \\
\text { et al. Hospital } \\
\text { Universitari Vall } \\
\mathbf{d}^{\prime} \text { Hebron, Spain }\end{array}$ \\
\hline Clinical imaging & & & & $\begin{array}{c}\text { RIEI } \\
\text { Cardiac echo performed }\end{array}$ \\
TTE performed & $151 / 160(94.4 \%)$ & $3111 / 3116(99.8 \%)^{* * *}$ & $640 / 677(94.5 \%)^{* * * *}$ \\
TEE performed & $85 / 160(53 \%)$ & $2793 / 3111(89.8 \%)^{* * *}$ & $478 / 677(70.6 \%)^{* * * *}$ \\
TTE positive & $148 / 160(92.5 \%)$ & $1808 / 3111(58.1 \%)^{* * *}$ & $395 / 640(62.0 \%)$ \\
TEE positive & $42 / 85(49.4 \%)$ & & $447 / 478(93.5 \%)^{* * * *}$ \\
PET CT performed & $130 / 148(87.8 \%)$ & & \\
Leucocyte scintigraphy & $46 / 160(28.8 \%)$ & $518 / 3116(16.6 \%)^{* * *}$ & \\
MDCT & $1 / 160(0.6 \%)$ & $38 / 3116(1.2 \%)$ & \\
\hline
\end{tabular}

Clinical imaging in the five studies. Cell markings with asterisks represent the statistical significance levels of the two-sample Pearson's chi-squared tests for the observed proportions. Reported significance levels for pairwise comparison between OLV Hospital and each of the four other registries individually are the following: no asterisk marking given for $p>=0.05$ and ${ }^{* * *}$ for $p<0.001$.

Table A7. Valvular lesions in CVCA registry.

\begin{tabular}{ccccc}
\hline & Aortic Valve & Mitral Valve & Tricuspid Valve & Pulmonal Valve \\
\hline Prosthetic & 56 & 22 & 3 & 0 \\
Vegetation & $66 / 160(41.3 \%)$ & $55 / 160(34.4 \%)$ & $14 / 160(8.8 \%)$ & $1 / 160(0.6 \%)$ \\
Vegetation median size in mm (IQR) & $10.0(7.0-13.0)$ & $12.5(9.0-20.0)$ & $16.0(10.0-20.0)$ & $18(18.0-18.0)$ \\
Vegetation range in mm & $2-35$ & $3-50$ & $6-25$ & - \\
Valve regurgitation $>=3 / 4$ & 33 & 17 & 16 & 0 \\
Leaflet perforation & 9 & 5 & 0 & 0 \\
Periannular abscess & 28 & 2 & 0 & 0 \\
Periannular pseudoaneurysm & 3 & 4 & 1 & 0 \\
Prosthetic valve dehiscence & 12 & 0 & 0 & 0 \\
Prosthetic valve obstruction & 2 & & \\
\hline
\end{tabular}

CVCA diagnostic imaging results.

Table A8. Complications.

\begin{tabular}{|c|c|c|c|c|c|}
\hline Registry & CVCA & EURO-ENDO & ICE-PCS & RIEI & $\begin{array}{l}\text { Fernández-Hidalgo et al. Hospital } \\
\text { Universitari Vall d'Hebron, Spain }\end{array}$ \\
\hline \multicolumn{6}{|l|}{ Complications (at admission or while under treatment): } \\
\hline Congestive heart failure & $69 / 160(43.1 \%)$ & $1288 / 3116(41.3 \%)$ & $876 / 2713(32.0 \%)^{* *}$ & $301 / 677(44.5 \%)$ & $205 / 438(46.8 \%)$ \\
\hline Intracardiac abscess & $31 / 160(19.4 \%)$ & $556 / 3116(17.8 \%)$ & $389 / 2707(14.0 \%)$ & $77 / 677(11.4 \%)^{* * *}$ & \\
\hline New conduction abnormality & $42 / 160(26.2 \%)$ & $459(16.0 \%) * *$ & $217 / 2695(8.0 \%)^{* * *}$ & & $84 / 438(19.1 \%)$ \\
\hline Persistent positive blood cultures & $21 / 160(13.1 \%)$ & $413 / 3088(13.4 \%)$ & $251 / 2699(9.0 \%)$ & & \\
\hline Pulmonary embolism & $10 / 160(5.6 \%)$ & $366 / 3116(11.7 \%)^{*}$ & & & \\
\hline Intracranial haemorrhage & $5 / 160(3.1 \%)$ & $138 / 3116(4.4 \%)$ & & $14 / 677(2.1 \%)$ & \\
\hline Vascular embolic event & $54 / 160(33.8 \%)$ & $1429 / 3116(45.8 \%)^{* *}$ & $1067 / 2781(38.6 \%)$ & $57 / 677(8.4 \%)^{* * * *}$ & \\
\hline Cerebral embolism & $38 / 160(23.8 \%)$ & $633 / 3116(20.3 \%)$ & & & \\
\hline Stroke/TIA & $30 / 160(18.8 \%)$ & $403 / 3116(12.9 \%)^{*}$ & $462 / 2727(17.0 \%)$ & & $89 / 438(20.3 \%)$ \\
\hline Splenic/Renal embolism/Spondylodiscitis & $14 / 160(8.1 \%)$ & $762 / 3116(24.5 \%)^{* * *}$ & & & \\
\hline Septic shock & $33 / 160(20.6 \%)$ & $494 / 3116(15.9 \%)$ & & & \\
\hline \multicolumn{6}{|l|}{ Valvular assessment: } \\
\hline Vegetation present: & $134 / 160(83.8 \%)$ & & $2406 / 2764(87.0 \%)$ & $605 / 677(92.0 \%)$ & \\
\hline AV & $66 / 160(41.3 \%)$ & & $1031 / 2741(38.0 \%)$ & & \\
\hline MV & $55 / 160(34.4 \%)$ & & $1125 / 2740(41.0 \%)$ & & \\
\hline TV & $14 / 160(8.8 \%)$ & & $323 / 2741(12.0 \%)$ & & \\
\hline PV & $1 / 160(0.6 \%)$ & & $29 / 2739(1.0 \%)$ & & \\
\hline Paravalvular abscess & $31 / 160(19.4 \%)$ & & $(15.0 \%)$ & $77 / 677(11.4 \%)^{* *}$ & \\
\hline Prosthetic valve complication & $57 / 160(35.6 \%)$ & & $518 / 2781(18.2 \%)^{* * *}$ & & \\
\hline Aortic valve affected & $77 / 160(48.1 \%)$ & $(49.5 \%)$ & & & $258 / 438(58.9 \%) *$ \\
\hline Mitral valve affected & $65 / 160(41 \%)$ & $(42.0 \%)$ & & & \\
\hline Tricuspid valve affected & $21 / 160(13.1 \%)$ & $(11.4 \%)$ & & & \\
\hline Pulmonal valve affected & $1 / 160(0.6 \%)$ & $(2.4 \%)$ & & & \\
\hline Multiple valves affected & $31 / 160(19.3 \%)$ & $(18.2 \%)$ & & & \\
\hline
\end{tabular}

Overview of IE complications and valvular assessments reported in the five studies. Cell markings with asterisks represents the statistical significance levels of the two-sample Pearson's chi-squared tests for the observed proportions. Reported significance levels for pairwise comparison between OLV Hospital and each of the four other registries individually are the following: no asterisks marking given for $p>=0.05,{ }^{*}$ for $p<0.05,{ }^{* *}$ for $p<0.01$ and ${ }^{* * *}$ for $p<0.001$. 


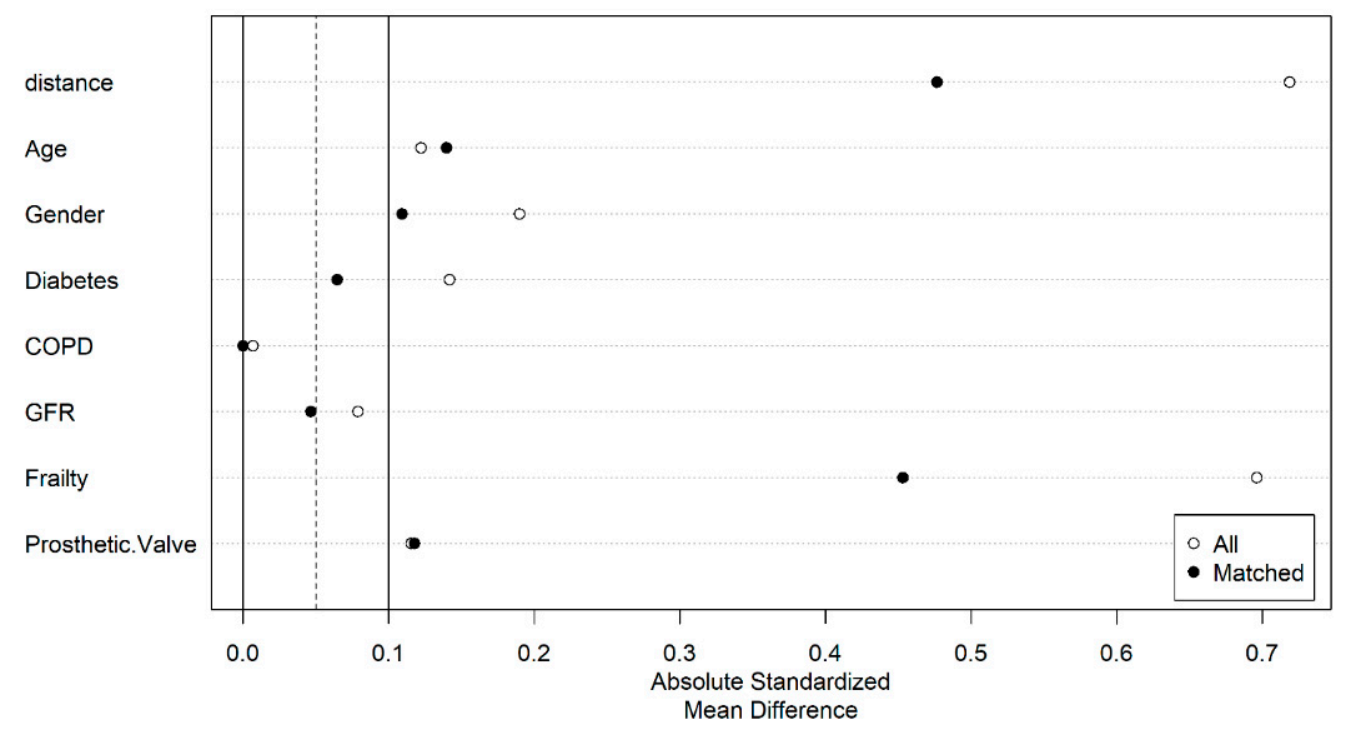

Figure A1. Figure with covariate balance before and after propensity score matching.
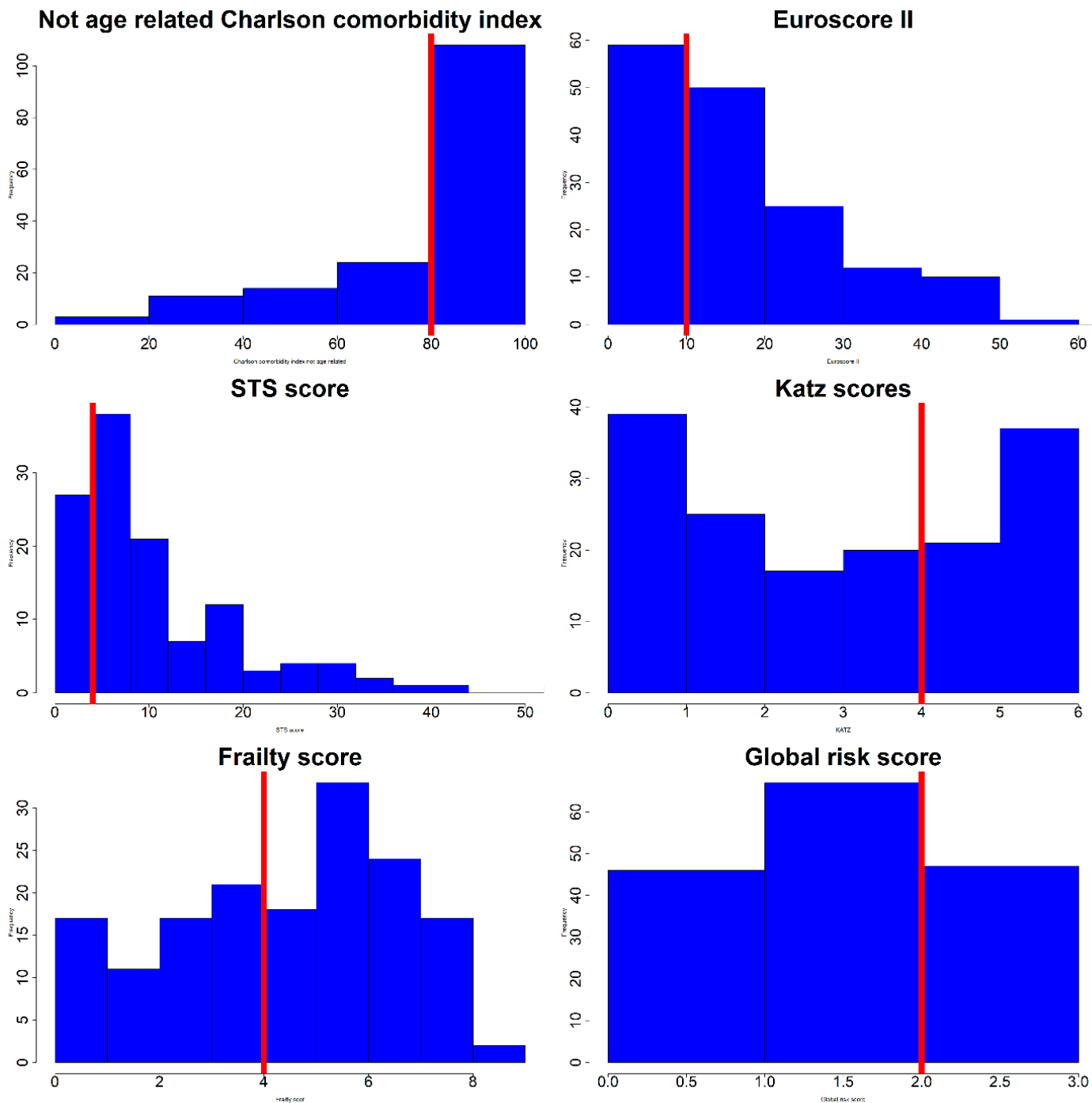

Figure A2. Risk scores of patients with IE from CVCA registry. Added vertical red line represents discrimination boundaries for elevated risk of mortality. 


\section{References}

1. Habib, G.; Erba, P.A.; Iung, B.; Donal, E.; Cosyns, B.; Laroche, C.; Popescu, B.A.; Prendergast, B.; Tornos, P.; Sadeghpour, A.; et al. Clinical presentation, aetiology and outcome of infective endocarditis. Results of the ESC-EORP EURO-ENDO(European infective endocarditis) registry: A prospective cohort study. Eur. Heart J. 2019, 40, 3222-3233. [CrossRef] [PubMed]

2. Habib, G.; Lancellotti, P.; Antunes, M.J.; Bongiorni, M.G.; Casalta, J.P.; Del Zotti, F.; Dulgheru, R.; El Khoury, G.; Erbaa, P.A.; Iung, B.; et al. ESC Guidelines for the management of infective endocarditis. Eur. Heart J. 2015, 36, 3075-3123. [CrossRef]

3. Nishimura, R.A.; Otto, C.M.; Bonow, R.O.; Carabello, B.A.; Erwin, J.P., III; Guyton, R.A.; O'Gara, P.T.; Ruiz, C.E.; Skubas, N.J.; Sorajja, P.; et al. AHA/ACC guideline for the management of patients with valvular heart disease: Executive summary a report of the american college of cardiology/american heart association task force on practice guidelines. Circulation 2014, 129, $2440-2492$. [CrossRef]

4. Mostaghim, A.S.; Lo, H.Y.A.; Khardori, N. A retrospective epidemiologic study to define risk factors, microbiology, and clinical outcomes of infective endocarditis in a large tertiary-cary teaching hospital. SAGE Open Med. 2017, 5, 1-9. [CrossRef]

5. Murdoch, D.R.; Corey, R.; Hoen, B.; Miro, J.M.; Fowler, V.G.; Bayer, A.S.; Karchmer, A.W.; Olaison, L.; Pappas, P.A.; Moreillon, P.; et al. Clinical presentation, etiology and outcome of infective endocarditis in the 21st century: The International Collaboration on Endocarditis-Prospective Cohort Study. Arch. Intern. Med. 2009, 169, 463-473. [CrossRef]

6. Cahill, T.J.; Baddour, L.M.; Habib, G.; Hoen, B.; Salaun, E.; Pettersson, G.B.; Schäfers, H.J.; Prendergast, B.D. Challenges in Infective Endocarditis. J. Am. Coll. Cardiol. 2017, 69, 325-344. [CrossRef]

7. Habib, G.; Lancellotti, P.; Erba, P.A.; Sadeghpour, A.; Meshaal, M.; Sambola, A.; Furnaz, S.; Citro, R.; Ternacle, J.; Donal, E.; et al. The ESC-EORP EURO-ENDO (European Infective Endocarditis) registry. Eur. Heart J. 2019, 5, 202-207. [CrossRef]

8. Cecchi, E.; Chirillo, F.; Castiglione, A.; Faggiano, P.; Cecconi, M.; Moreo, A.; Cialfi, A.; Rinaldi, M.; Del Ponte, S.; Squeri, A.; et al. Clinical epidemiology in Italian Registry of Infective Endocarditis (RIEI): Focus on age, intravascular devicesd and enterocci. Int. J. Cardiol. 2015, 190, 151-156. [CrossRef] [PubMed]

9. Fernandez-Hidalgo, N.; Almirante, B.; Tornos, P.; Gonzalez-Alujas, M.T.; Planes, A.M.; Galinanes, M.; Pahissa, A. Immediate and long-term outcome of left-sided infective endocarditis. A 12-year prospective study from contemporary cohort in a referral hospital. Clin. Microbiol. Infect. 2012, 18, E522-E530. [CrossRef]

10. Kastner, C.; Armitage, J.; Kimble, A.; Rawal, J.; Carter, P.G.; Venn, S. The Charlson comorbidity score: A superior comorbidity assessment tool for the prostate cancer multidisciplinary meeting. Prostate Cancer Prostatic Dis. 2006, 9, 270-274. [CrossRef] [PubMed]

11. Katz, S.; Down, T.D.; Cash, H.R.; Grotz, R.C. Progress in the development of the index of ADL. Gerontologist 1970, 10, 20-30. [CrossRef] [PubMed]

12. Rockwood, K.; Song, X.; MacKnight, C.; Bergman, H.; Hogan, D.B.; McDowell, I.; Mitnitski, A. A global clinical measure of fitness and frailty in elderly people. Cmaj 2005, 173, 489-495. [CrossRef] [PubMed]

13. Slipczuk, L.; Codolosa, J.N.; Davila, C.D.; Romero-Corral, A.; Yun, J.; Pressman, G.S.; Figueredo, V.M. Infective endocarditis epidemiology over five decades: A systematic review. PLoS ONE 2013, 8, e82665. [CrossRef] [PubMed]

14. DeSimone, D.C.; Tleyjeh, I.M.; Correa de Sa, D.D.; Anavekar, N.S.; Lahr, B.D.; Sohail, M.R.; Steckelberg, J.M.; Wilson, W.R.; Baddour, L.M. Temporal trends in infective endocarditis epidemiology from 2007 to 2013 in Olmsted County, MN. Am. Heart J. 2015, 170, 830-836. [CrossRef] [PubMed]

15. Ambrosioni, J.; Hernandez-Meneses, M.; Téllez, A.; Pericàs, J.; Falces, C.; Tolosana, J.M.B.; Vidal, B.; Almela, M.; Quintana, E.; Llopis, J.; et al. The changing epidemiology of infective endocarditis in the twenty-first century. Curr. Infect. Dis. Rep. 2017, 19, 21. [CrossRef] [PubMed]

16. Chambers, H.F.; Bayer, A.S. Native-Valve Infective Endocarditis. N. Engl. J. Med. 2020, 383, 567-576. [CrossRef] [PubMed]

17. Gomes, A.; Glaudemans, A.W.J.M.; Touw, D.J.; van Melle, J.P.; Willems, T.P.; Maass, A.H.; Natour, E.; Prakken, N.H.J.; Borra, R.J.H.; van Geel, P.P.; et al. Diagnostic value of imaging in infective endocarditis: A systematic review. Lancet Infect. Dis. 2017, 17, e1-e14. [CrossRef]

18. Que, Y.A.; More, P. Infective endocarditis. Nat. Rev. Cardiol. 2011, 8, 322-336. [CrossRef] [PubMed]

19. Gibbons, E.F.; Huang, G.; Aldea, G.; Koomalsingh, K.; Klein, J.W.; Dhanireddy, S.; Harrington, R. A Multidisciplinary Pathway for the Diagnosis and Treatment of Infectious Endocarditis. Crit. Pathw. Cardiol. 2020, 19, 187-194. [CrossRef] [PubMed]

20. Chambers, J.; Sandoe, J.; Ray, S.; Prendergast, B.; Taggart, D.; Westaby, S.; Arden, C.; Grothier, L.; Wilson, J.; Campbell, B.; et al. The infective endocarditis team: Recommendations from an international working group. Heart 2014, 100, 524-527. [CrossRef] [PubMed] 